\title{
The dialogue between Didaktik and curriculum studies within mainland China
}

\section{Bangping Ding and Xun Su}

\section{Introduction}

International and intercultural dialogues in education science between the advocates of Didaktik (didactics) and of curriculum studies are a frequent occurrence all over the world (Hopmann, 2015; Lee and Kennedy, 2017; Westbury, Hopmann and Riquarts, 2000). In mainland China, however, these encounters have taken place within one country (Ding, 2011, 2015; Ding and Wang, 2017). Modern Western schooling systems were adopted in China early in the twentieth century to replace traditional systems and meet the pressing demand for trained schoolteachers. By turns, first the German Didaktik approach and then, within 20 years, the Anglo-American discipline of curriculum studies were adopted, with few modifications, as pedagogical theories. After the period of the Cultural Revolution, where influences came from the Soviet Republic, Anglo-American curriculum studies began to be reintroduced in the Chinese educational landscape; and with the turn of the millennium, calls for the re-establishment of educational science (or simply pedagogics) have been in the air in mainland China, and reflective discourses on the rebuilding of Chinese didactics have come to the fore (Ding, 2009; Xu, 2019). Hence, the situation today is, as in the Nordic countries, that didactics and curriculum studies go hand in hand as pedagogical approaches in the educational landscape of mainland China, reflecting the fact that both systems took root there (Deng, 2013, 2015; Ding, 2015; Zhang, 2017). Retrospectively, we find that the dialogue between didactics and curriculum studies in this country may perhaps have tended towards the simplistic, rather than exhibiting the depth and complexity called for by Pinar (Pinar, 2011, 2014). As a result, a number of misreadings and misunderstandings of both disciplines have arisen among Chinese educators and educational researchers, even including didacticians. This has had a significant impact on the policy formation and implementation of recent curriculum reforms: curriculum studies are currently predominant in the realm of theory, with many Chinese educational policymakers and curriculum theorists considering didactical theories to be outdated or even anachronistic.

For this reason, we argue that it is of the first importance that didactics should be conducted as an independent university subject with the full range and 
depth of academic reflection in the context of mainland China. Our objective here is not just the rediscovery of the true quintessence of didactics in a form that can complement Anglo-American curriculum studies, but for the essential elements of both disciplines to be integrated with traditional educational culture and/or wisdoms. To this end, this chapter will review in some depth the historical trajectories by which first didactics and then curriculum studies were introduced and localised in mainland China. This historical process was not only long and complicated but also fraught with selections and options that resulted from cultural misunderstandings as well as educational needs.

In the following sections, we will first introduce the historical background against which models and theories from German Didaktik and from AngloAmerican curriculum studies were introduced in China at different points in the twentieth century. We will then present the research method for the study: that is, qualitative content analysis of didactics and subject didactics textbooks. The results of the study will then be presented. Next, issues arising from the research questions and the analyses will be discussed, with the aim of shedding light on current and future issues in the conceptualisation and re-establishment of the new, mixed, and integrated pedagogical discipline, Curriculum and Didactics. It is hoped that this integrated discipline, based on the analysis and re-conceptualisation of modern didactics and curriculum theories and on a reflection on Chinese didactics, will embody the true Chinese spirit of pedagogical and educational theorising. Finally, some concluding remarks will be presented.

\section{Historical background and context}

As has been described elsewhere (Deng, 2015; Ding and Wang, 2017; Zhang, 2017), German Didaktik was originally introduced to China by way of Japan when Western school systems were transplanted in China in the first decade of the twentieth century. What was called didactics (and/or pedagogics) at the time was part of the teacher preparation programme so badly needed for the newly established schools and colleges of teacher education (the so-called normal schools). After the May Fourth Movement of 1919, China broke with Japan politically, ideologically, and educationally, and in 1922 the 6-3-3-4 school system of was adopted from the United States (six years of primary school, three years of junior high school, three years of senior high school, and four years of college/university undergraduate study), drawing on the work of John Dewey and progressive educational ideas. For the next three decades, until 1949, American educational influence was predominant in China, finding its theoretical expression in the emerging field of educational study that was Anglo-American curriculum studies. In these circumstances, the theory of Didaktik/didactics adopted in the first two decades of the century receded into the background of Chinese educational theory and practice and AngloAmerican curriculum theory became the major influence on educational developments in mainland China. 
The first half of the twentieth century, therefore, saw the encounter between didactics and curriculum studies in the Chinese educational landscape, and a resultant 'dialogue' between them. It is necessary and indispensable to explore the traces and/or tendencies of this encounter, because the educational ideas and theories that are influential in a country during a given period are not isolated, nor are they without influence on wider social and historical movements and ideas. In our reflection on, and reconstruction of, didactics and curriculum studies for contemporary teacher education in mainland China today, we have to draw upon the historical experience of earlier generations of Chinese educationalists. These scholars, as we saw in our preliminary study of didacticians and curriculum scholars in the first part of the twentieth century (Ding, 2009, 2015; Ding and Wang, 2017), not only introduced European Didaktik and Anglo-American curriculum theories, but tried with varying degrees of success to combine them with Chinese national needs in educational practice; they even tried to formulate their own theories of didactics and curriculum. In this sense, the Sinicisation of Didaktik/didactics and curriculum studies now has been ongoing for more than a century in China.

Next, our study moves to the second half of the twentieth century and the resurfacing of didactics in Chinese educational discourses, this time introduced from the Soviet Union. With the shift of political regime in China, during the three decades from 1949 to 1979 curriculum studies was abandoned as a field of study. In train with mainland China's alignment with the Soviet Union, Soviet didactics and pedagogics were now embraced as the correct educational disciplines for the teacher education programme, replacing Dewey's theory of education and progressive educational theory in general (including curriculum studies). As the German Didaktik of the Herbartian school had been supplanted by Anglo-American educational theories, Soviet/Russian didactics (in the form of Kairov's Pedagogy textbook) was now influential for just one decade between 1950 and 1960. Following the Sino-Soviet political and ideological rift, however, it was severely criticised during the Cultural Revolution of 1966-1976. But with the opening and reform of China in 1978, Kairov's Pedagogy was re-evaluated in academic circles, and the subsequent three decades from 1979 to 2009 witnessed the flowering of Chinese didactics and subject didactics as pedagogical subdisciplines for a teacher education knowledge base, now impacted once again both by contemporary German Didaktik and by Soviet didactics (Xu, 2019).

Meanwhile, following the resumption of diplomatic relations with the United States in 1979, curriculum studies re-emerged after 30 years of proscription as a pedagogical field of study in mainland China during the 1980s and 1990s. Curriculum textbooks published during the nationalist period before 1949 were now reissued, and a new generation of curriculum scholars grew to maturity and formed research groups in teacher education colleges/universities. In the 1990s they founded the Association for Curriculum Studies of China (Zhang, 2017). Although many of these scholars had first studied in the didactics camp, 
at this time their academic interests turned to curriculum studies and they found themselves among curriculum scholars. By the same token, some of the didacticians found themselves attracted by the curriculum discourses translated from the US curriculum literature and went on to incorporate curriculum theories into their own work on didactics (e.g. C. S. Wang, 1985).

Thus, a confluence emerged in the 1980s in Chinese educational thinking between German Didaktik (including Martin Wagenschein's exemplary teaching methods and Wolfgang Klafki's critical categorical didactics) and AngloAmerican curriculum theories (including Tyler's theory of curriculum, Pinar's theory of reconstructionist curriculum, Doll's post-modern curriculum theory, just to name a few). At this confluence, a blended field of pedagogical study was thus created in mainland China, called Curriculum and Didactics. This new field of Curriculum and Didactics, together with subject curriculum and didactics for various school subjects (physics didactics, chemistry didactics, biology didactics, mathematics didactics, and Chinese language didactics), became a new subdiscipline among the educational sciences as a university discipline in its own right - although curriculum studies and didactics still continued to be researched separately by some educationalists.

The aims of the present study are to reflect on the nature of the dialogue between Didaktik/didactics and curriculum studies in mainland China over the past four decades, and to address the question of how this dialogue has become problematic through misreadings and misunderstandings by influential researchers in didactics and curriculum. This question has not received much attention within educational circles in mainland China, because most Chinese researchers in both camps seem to argue that the two fields of study originally adopted from the West, although distinct, are interrelated, as if they did not exemplify profound cultural or national differences.

In view of these aims, the specific research questions of the study are as follows:

1 What were the traces and/or tendencies in Chinese didactics and curriculum studies?

2 How did didactics and curriculum studies encounter one another and interact in the academic field of education in mainland China?

\section{Methodological considerations}

The method used to address these questions is qualitative content analysis, which reveals some traces and/or tendencies in the encounter between Didaktik/didactics and curriculum studies in the Chinese landscape of education. "Content analysis involves reading and judgment", as Cohen, Manion and Morrison state in their Research Methods in Education (2000, p. 284). Because space is limited, we have confined ourselves to the content analysis of selected textbooks as exemplars among those published over the past four decades in the 
fields of general didactics and subject didactics. Two major didactics textbooks, one on general didactics and one on subject didactics, were chosen to identify the traces and/or tendencies in order to show how Chinese didacticians have dealt with issues of teaching/learning and curriculum in their works on general didactics and subject didactics.

\section{Content analysis of Chinese didactics textbooks}

\section{Chinese general didactics textbooks}

The first selection of textbooks from general didactics comprises two works: A Seminar Notes on Didactics (Jiaoxuelun Gao, 教学论稿) by Professor Ce-san Wang (1928-2017) of Beijing Normal University, first published in 1985 and running into several later editions, and Didactics (Jiaoxuelun, 教学论) by Professor Bing-de Li (1912-2005) of Northwest Normal University, first published in 1991 and the most-used university textbook of its kind. For space reasons, in the present chapter, our content analysis will be limited to the first of these two works, Wang's textbook.

Wang has been teaching without interruption since the early 1950s at the Faculty of Education at Beijing Normal University, one of the top research universities training future educational researchers as well as schoolteachers (and other professionals). His textbook is based on his lecture notes, prepared as an elective course in 1979 and eventually published in textbook form. The author describes his book as featuring "a discussion and exploration of theoretical issues and problems in didactical research" (C. S. Wang, 1985, p. 1, authors' translation). As a textbook of general didactics, A Seminar Notes on Didactics is highly regarded by students of education studies in mainland China, as it represents a breakthrough in numerous respects.

In the first place, rather than merely presenting teaching/learning methods for students of education and/or prospective teachers, the book stands out for its theoretical exploration. In that sense, it is the most significant work in Chinese didactics to have been published in mainland China. Although Johann Amos Comenius' Didactica Magna (Great Didactic) had been published in Chinese translation in the 1930s and the Chinese version of Johann Friedrich Herbart's General Pedagogy (1806) had also been familiar to teachers and educationists in China in the first half of the twentieth century, the predominant influence among foreign pedagogical works stemmed from the United States, especially after the visits by John Dewey and his progressive followers (such as William H. Kilpatrick) to China in 1919 and the 1920s respectively. In the field of pedagogical studies, therefore, Anglo-American curriculum studies and general methods of teaching or instruction were more influential than German Didaktik had been, even if Herbart's formal steps of instruction became rooted in the practice of classroom teaching in China at the beginning of the twentieth century. 
During the 1950s, however, owing to the shift in political regime, it was Soviet pedagogy that abruptly superseded the influence of Anglo-American educational science (and especially curriculum studies). Soviet official pedagogics were very popular among educational researchers and schoolteachers; Kairov's Pedagogy (1953) and his didactics in that work were regarded as the most 'scientific' theory of all. That popularity was short-lived, however. From 1957, China started to explore its own way of building a socialist country, as distinct from the Soviet model, while resisting the overwhelming influence from the Soviet Union. That exploration, however, was in turn cut short by the Cultural Revolution of 1966-1976, which prohibited Chinese educational researchers in general and didacticians in particular from developing Chinese didactics of any kind. Against this background, it can be said that Ce-san Wang's textbook was by some margin the first ever comprehensive and influential work of its kind in mainland China. It differed markedly from, for example, Chinese works on teaching/learning methods that were written on the basis of Anglo-American works published during the 1930s and 1940s on teaching/ instruction theories and methods. A further difference from translated works on didactics from the Soviet Union was that it was partly based on the Chinese culture of education and Chinese traditions of wisdom (Zhang, 2017).

A second remarkable feature is that while Wang's textbook tries to create a systematic structure for Chinese didactics as an academic subdiscipline with Chinese educational culture in mind, it is still redolent of the influence of Kairov's Pedagogy (1953). For one thing, the textbook acknowledges that a Marxist didactics was established in the Soviet Union and other Eastern Bloc countries, and Wang is ready to follow in the steps of this Marxist tradition in didactical research. For another, Wang had structured his textbook of didactics along a similar model to Soviet didactics, that is, dealing with such topics as basic concepts in didactics (Chapter 4); the process of teaching/learning (Chapter 5); principles of teaching/learning, methods of teaching/learning (Chapter 10); modes of teaching/learning (Chapter 11); forms of organisation in teaching/ learning (Chapter 12); and assessment criteria for student assignments (Chapter 13). These discourses in Chinese didactics reflect their origin in Russian didactics, and implicitly, therefore, in continental European Didaktik/didactics. There were however changes in and additions to the content of Wang's textbook: American curriculum theory - a different Western educational culture to that of European Didaktik or Soviet/Russian didactical culture - was also subordinated to Chinese didactics. For this reason, Wang's Chinese didactics is regarded as a model of 'large didactics' by other educational researchers in China (e.g. Ding, 2009; Ding and Wang, 2017).

Third, Wang made a significant contribution to integrating Chinese pedagogical culture into Chinese didactics. For instance, in defining the concept of teaching/learning (jiaoxue, 教学), one of the foundational concepts in didactics, Wang contended that although there are many different definitions of it in the literature, "teaching/learning is always an integrating activity of teaching and 
learning" (C. S. Wang, 1985, p. 89, authors' translation). He further criticised the dichotomy between teaching and learning as follows:

[I]n didactical (i.e. teaching-learning) activities, it is plain, of course, that there is either separate teaching or separate learning, and that one cannot take place without the other; but on this special occasion teaching cannot be detached from learning, and so teaching-learning is always a common activity involving one another, rather than simply teaching plus learning. Teaching and learning are two sides of the same coin, and so they are dialectical and integrating, so to speak.

(p. 89, authors' translation)

In defending this idea of the inseparability of teaching and learning, Wang cites Fu-zhi Wang (1619-1692), a philosopher of the Ming dynasty (AD 13681644), who remarked:

[L] earning is to learn what the teacher imparts, so learning is not to teach; whereas teaching is to teach students to learn what is taught by the teacher, so teaching is not to learn, of course.

(quoted in C. S. Wang, 1985, p. 90, authors' translation)

Wang illustrates this principle by saying:

When students are self-studying in the classroom in the absence of the teacher, or when students are doing assignments at home, is their 'learning' considered to be separated from 'teaching'? No! Take another example, when a teacher is marking students' compositions in the staffroom with no students around, is this kind of 'teaching' detached from his/her students' 'learning'? No!

(p. 90, authors' translation)

Following this analysis, Wang defined the concept of teaching/learning as follows:

By teaching-learning is meant an activity integrating teaching given by the teacher with learning on the part of the students; in this shared activity, students master a certain body of knowledge and skills, meanwhile they also gain development of body and mind and develop moral character.

(pp. 88-89, authors' translation)

Fourth, Wang was the first Chinese didactician to draw on curriculum theory to enrich Chinese didactics research. The table of contents indicates that three of the chapters (Chapters 7, 8, and 9) deal with curriculum issues in a way 
that subordinates curriculum studies to Chinese didactics. In Chapter 7, for example, Wang contends that:

We hold that curriculum can be looked upon as the arrangement of instructional content, and that didactics without instructional content is empty, and curriculum is in fact subjected to the law of instructional process.

(pp. 165-66)

In his own research on didactics, therefore, Wang did not distinguish either between didactics and curriculum or between didacticians and curriculum theorists. In Chapter 2, for example, Wang places the American psychologist and curriculum reformer Jerome Bruner (1915-2016) side by side with Russian didacticians such as I. V. Zankov (1901-1977), asserting that "Bruner's didactical thought [sic] lies in his curriculum theory" (p. 26). On the other hand, although curriculum study did not constitute an independent field of research in Soviet pedagogical sciences at the time, the significant Russian idea of obrazovanie (образование, similar to the German idea of Bildung) concerning the content of instruction in Soviet didactics is nearly absent from Wang's work (or any other works by Chinese didacticians, for that matter). The pre-1949 nationalist era saw few, if any, attempts to establish Chinese didactics other than by introducing the Anglo-American curriculum theories and their methods of instruction. This meant that once the time was appropriate for Chinese didacticians like Wang to build a didactics as a theoretical subdiscipline within pedagogics or the educational sciences, they found it necessary to make use of Anglo-American curriculum theories as an element in their attempts to found Chinese didactics. But because the two approaches originated in two distinct and separate Western pedagogical and educational cultures, these attempts led to frequent misunderstandings of both Didaktik/didactics and curriculum studies (Ding, 2009; Ding and Wang, 2017).

A fifth remarkable feature is that one can readily see in Wang's didactics that he tried to establish Chinese didactics on the foundation of Marxist philosophy: that is, on dialectical and historical materialism, which was regarded as the guiding rationale for all research in human and social sciences, including didactical study. Wang states:

The main characteristics of Marxist didactics rest in the recognition that dialectical and historical materialism - most of all dialectical materialist epistemology of reflection - is the foundation of methodology.

Here Wang is acknowledging that Marxist didactics was originally founded in the Soviet Union and his wish to continue this tradition of Marxist didactics in mainland China. A few years later, Wang and colleagues published a monograph entitled Theory of Knowing in Teaching/Learning (教学认识论) 
(C. S. Wang, 1988/2002), which systematically expounds the theoretical foundation of Chinese didactics from a Marxist epistemological point of view.

A sixth and final remarkable feature is that Wang's textbook lays the groundwork for Chinese didactics. He makes great efforts to construct a version of Chinese didactics by integrating Soviet didactics, American curriculum theories, and the rich Chinese educational culture and wisdom traditions. In particular, he emphasises the value of teaching/learning, an important idea that permeates Confucian works on education. Such teaching/learning notions as 'Teaching is half of learning' (jiaoxue ban, 教学半), 'Teaching and learning will enhance each other' (jiaoxue xiangzhang, 教学相长), and 'Teaching students by using the elicitation method and helping them infer from examples' (qifashi jiaoxue, 启发式教学) are reactivated and transformed in Wang's textbook of didactics. Most important of all, he insists that Chinese didactics should be a theoretical pedagogical discipline. He thus distinguishes between general didactics (jiaoxuelun, 教学论) and methods of teaching/learning (jiaoxuefa, 教学法) (Ding, 2015).

\section{Chinese subject didactics textbooks}

The past four decades have also seen considerable growth in subject didactics in the colleges and universities that train primary and secondary school teachers in mainland China. Like their counterparts in continental European countries, however, researchers in subject didactics (Fachdidaktik) are located within their respective academic departments rather than as an independent discipline. A certain tension thus exists between researchers in general didactics and subject didactics, based on the somewhat different training and competences of the two groups (Strømnes, Rørvik and Eilertsen, 1997).

Like their colleagues in general didactics, researchers in subject didactics (including chemistry didactics, physics didactics, biology didactics, mathematics didactics, and Chinese language didactics) in mainland China since the 1980s have to an extent misread and misunderstood subject didactics and curriculum studies. Rather than recognising curriculum studies as an independent discipline, they have sought to integrate ideas gleaned from Anglo-American curriculum studies with subject didactics. This can be seen in the textbooks edited by subject didactics researchers for teacher education programmes. While the titles of these textbooks use the term 'didactics' rather than 'curriculum', their content is replete with discourses originating in Anglo-American curriculum studies, blended with some content of curriculum studies as well. One typical example is a widely used textbook entitled Didactics of Chemistry, edited by Professor Zhixin Liu (b. 1928) (Wei, 2012), a famous specialist in the field of Didactics of Chemistry in China, now a retired professor in the College of Chemistry, Beijing Normal University.

Published in 1990, the first edition of this textbook is pervaded by discourses from the field of didactics, including teaching syllabus, teaching plans, 
and teaching content. Although the word 'curriculum' is used in Chapter 1, entitled "The Setup and Content of the Chemistry Curriculum", the reference here is to the curriculum of required courses in secondary schools, rather than to the sense used in curriculum studies, which is of a much richer connotation (Liu, 1990). In addition, this textbook is visibly deeply influenced by the Soviet-led chemistry didactics of an earlier era. In the earliest, pre-publication manuscript of the text in 1957, the structure and organisation of the book were mainly borrowed from similar textbooks translated and published in the former Soviet Union during the 1950s honeymoon period between the two countries (Wei, 2012). Four chapters (Chapters 3, 10, 11, and 12) of the 1900 textbook edition elaborate on the chemistry teaching skills and chemical knowledge that a chemistry teacher should master, while one chapter (Chapter 4) introduces teaching about dialectical materialism and patriotism into the teaching of chemistry (Liu, 1990). Interestingly, however, the Russian concept of obrazovanie, fundamental to Soviet didactics and subject didactics, cannot be found in the first edition of Didactics of Chemistry.

By contrast, in the most recent edition of the Didactics of Chemistry, published in 2018, discernible differences and changes have been introduced in the intervening decades since first publication. There are several notable differences. First, the 2018 edition has been very heavily influenced by AngloAmerican curriculum studies in discourse. The discourses of didactics that informed the first edition - teaching plans, teaching syllabus, teaching content, and teaching assessment - have disappeared, and instead the salient discourses are taken from curriculum studies: for example, curriculum development, curriculum reform, and curriculum standard. Second, the new edition has also been considerably influenced by Anglo-American curriculum studies in terms of substance. Methods of subject teaching and learning - including teaching methods (Chapter 4), teaching skills (Chapter 5), chemistry experiments teaching (Chapter 6), and the inquiry-based teaching of chemistry (Chapter 7) - have been added. Additionally, some content has been incorporated from AngloAmerican curriculum studies (Chapters 2 and 3): Chapter 2 refers to the compilation and renovation of the chemistry curriculum, and Chapter 3 to the design and content construction of chemistry textbooks (Liu, 2018). Third, the renovation of the chemistry curriculum discussed in Chapter 2 is clearly influenced by the recent Chinese curriculum reforms during the period 2001 to 2016. Fourth, a chapter on theories of chemistry learning (Chapter 8) has been added, an obvious influence from Anglo-American learning theories, which centre on the general principles of learning. Fifth, knowledge of the content of chemistry, measurement and evaluation of chemistry teaching, and teaching of chemistry exercises and revision, all of which appeared in the first edition, have been expunged from the fifth edition (Liu, 1990, 2018). This too may be due to the influence of Anglo-American teaching theory, which concentrates on effective teaching methods rather than the teaching of content and practical classroom teaching (Ding, 2015). Finally, the integration of information 
technology with the chemistry curriculum (Chapter 9) and the professional development of chemistry teachers (Chapter 10) are also newly introduced in the fifth edition.

In conclusion, it is reasonable to say that the fifth edition of the textbook has moved decisively towards the Anglo-American discipline of curriculum studies and its theories of learning and teaching, leaving the older, Soviet-style chemistry didactics behind. The resulting work, however, turns out to be something of a mixture: that is, the 'Curriculum and Didactics' of chemistry (or physics, biology, mathematics, or the Chinese language), as the discipline is known today. This simplistic blending of content and discourses from subject didactics and curriculum studies indicates that a thoroughgoing and cross-cultural dialogue between curriculum and didactics has yet to take place in the field of subject didactics in mainland China today.

\section{Back to the research questions}

We turn back to our research questions. The first question asks, what are the traces and/or tendencies about Chinese didactics and curriculum studies?

In contrast to Germany, where Didaktik originated and where curriculum studies was in vogue only for a short time in the 1970s, and in contrast also to the United States, where curriculum studies came into being from an indigenous culture of pragmatism, in China both didactics and curriculum studies were adopted children, gradually indigenised from the early twentieth century as part of the Chinese modernisation programme. Politics played a huge role in the indigenisation of these disciplines, especially in the latter half of the century, when shared beliefs in communism in both countries led to the didactics (and pedagogics) of the former Soviet Union being chosen as the dominant pedagogical and educational theory, severing the earlier-established traditions of German Didaktik and Anglo-American educational science in general and curriculum studies in particular. It is also important to bear in mind that continual political disruption from the 1950s up to 1976 - in the correction movement of intellectuals, the Great Leap Forward, and the Cultural Revolution - largely prevented researchers and university teachers from doing any research in their fields, let alone publishing work that might be socially valuable or creative.

Over the past four decades, however, the political environment for academic work in mainland China has very much improved for Chinese researchers and academics, characterised as it has been by reform and by opening up. International academic exchanges and cooperation have taken place, and Chinese researchers and academics have been able to visit other countries, with their international counterparts frequently invited to their home universities in return. It is in this period of Chinese modern history that Chinese didactics and curriculum studies have made great progress in research and with the completion of many $\mathrm{PhD}$ projects in the field. According to the didactician 
Professor Ji-cun Xu (2019) of Shandong Normal University, there were only 80 graduates with a master's degree in the programme of Curriculum and Didactics and five PhDs in 1997, but by 2005 these numbers had increased to 500 and 38 respectively. Between 2006 and 2010, there were more than 3,500 graduates with a master's degree in the programme of Curriculum and Didactics and nearly 300 with a $\mathrm{PhD}$, and more than half of the latter were graduates in a subject curriculum and didactics (such as the Chinese language, mathematics, foreign languages, biology, chemistry, or physics).

Now we turn to the second research question: how did Chinese didactics and curriculum studies encounter one another and interact in the academic field of education in mainland China?

Chinese didactics gradually evolved as a field of study from the mother discipline of pedagogics into its independent form (C. S. Wang, 1985), including various subdisciplines such as curriculum studies and subject didactics, and finally converging over the last 40 years in a comprehensive discipline called Curriculum and Didactics (Xu, 2019). The 1980s and 1990s witnessed the rapid development of didactics as an independent subdiscipline among educational sciences in mainland China. In 1985, Chinese didacticians organised themselves into the National Association of Didactics within the Chinese Society of Education, thereby promoting the rapid development of the discipline. In 1997, a group of curriculum researchers networked and went on to establish the National Association of Curriculum Studies, also within the Chinese Society of Education, claiming independent identity of curriculum studies as a subdiscipline of educational sciences in mainland China. However, also in 1997, the Council of the State Commission of Academic Degrees and the Ministry of Education determined that didactics and curriculum studies were to be merged in the combined subdiscipline of Curriculum and Didactics. A new generation of master's and $\mathrm{PhD}$ students have now graduated within the new Curriculum and Didactics graduate education programme in colleges and universities.

In spite of their official merging, however, there have been operational difficulties in the harmonious combination and integration of the two fields of study, stemming as they do from two very different educational cultures. For one thing, Chinese specialists in both schools tend to use their own distinct discourses. When they find themselves in different linguistic contexts, they consequently tend to talk past each other. For example, in didactics, the following expressions are used: teaching/learning (rather than instruction or learning), teaching plans, assessment/evaluation of teaching/learning, reform in teaching/ learning, process of teaching/learning, principles of teaching/learning, and methods of teaching/learning. In curriculum studies, on the other hand, a parallel but different set of expressions is used: curriculum standards, curricular implementation, curriculum assessment/evaluation, and curriculum reform. This dichotomy between terminologies creates difficulties not only for practising teachers in their communications with academics but also for didacticians and their curriculum counterparts when they compare notes on professional occasions. Given this situation, the construction of a harmonious and blended 
discipline of Curriculum and Didactics is proving a difficult task for Chinese educational scholars. In this respect we would welcome learning from our international and intercultural dialogues, and particularly from our colleagues in the Nordic countries.

\section{Conclusion}

The development of the new discipline of Curriculum and Didactics in mainland China is of course rooted in reforms of teaching, learning, and schooling. As a result, many pedagogical problems and issues have arisen in the reform process. For example, as part of the current reform of science education in schools, inquiry-based teaching and learning has been promoted since the turn of the millennium as the curricular content of school science and as a better mode of pedagogy. In spite of this policy, however, a phenomenon that has been termed pseudo-inquiry (Jiang, 2015) has surfaced in many science classrooms across the country in recent years, whereby science lessons in the classroom have frequently been characterised by seemingly hands-on and cooperative learning. How are researchers in the field of Curriculum and Didactics in mainland China to conceptualise such challenges and deviations from the objectives of the science curriculum reforms? So far, neither Chinese didactics nor curriculum studies in their existing form have proved capable of resolving such challenges in a satisfying way. One possibility is that international and intercultural scholarly dialogue may help to facilitate the emergence of the new Curriculum and Didactics discipline in such a way that these problems can be resolved in a practical way.

Another aspect importantly requiring study is the need to build a Chinese culture of education, with the new and blended discipline of Curriculum and Didactics as an integral part. By the Chinese culture of education, we refer to the traditional culture related to teaching, learning, and schooling, and especially to Confucianism in terms of the way of thinking as regards education. For example, the concept of 'Chinese harmonism'1 (Z-H. Wang, 2012) is one of the most important philosophical cornerstones of this tradition. In our view, this concept could be extremely useful as a tool in constructing and developing the new blended discipline of Curriculum and Didactics (Ding and Wang, 2017). As Ding and Wang put it:

As an epistemological way of knowing, the concept Chinese harmonism does not try to treat reality as the same; rather, it teaches people to discriminate between the differences.

And again:

[I]t recognises, first, the differences of the ideas, and then takes advantage of the differences to innovate and make something new and valuable, just 
like the chemical change that takes place in different elements when they happen to encounter each other.

\section{Note}

1 'Harmonism' is a new word, which is meant to indicate the ancient Chinese idea expressed in the phrase 'he er bu tong' (和而不同), which was put forward by Confucius. In Chinese, 'he' (和) is meant to be harmony, while 'tong' (同) is just the opposite; the former is an epistemological way of creative knowing, trying to absorb various elements from different things to create something new and valuable, whereas the latter cannot do so. (See more of the idea 'Chinese harmonism' in Z-H. Wang, 2012.)

\section{References}

Cohen, L., Manion, L. and Morrison, K. (2000). Research methods in education, 5th ed. London: Routledge Falmer.

Deng, Z. (2013). The practical and reconstructing Chinese pedagogics. Journal of Curriculum Studies, 45(5), pp. 652-667. https://doi.org/10.1080/00220272.2013.818718.

Deng, Z. (2015). Content, Joseph Schwab and German Didaktik. Journal of Curriculum Studies, 47(6), pp. 773-786. https://doi.org/10.1080/00220272.2015.1090628.

Ding, B. P. (2009). Reconsidering the relation between didactics/teaching theories and curriculum theories: A comparative perspective. Comparative Education Review, 12, pp. 44-49 [In Chinese].

Ding, B. P. (2011). The distinction between the German Didaktik and the Anglo-American teaching theory: A cross-cultural study. Comparative Education Review, 7, pp. 7-76 [In Chinese].

Ding, B. P. (2015). Analysis of the relationship of 'Didactics' and 'Methods of teachinglearning': A perspective from comparative didactics. Journal of Educational Studies, 11(5), pp. 53-64 [In Chinese].

Ding, B. P. and Wang, F. (2017). Didactics meets curriculum studies in the context of teacher education in mainland China: A historical and comparative perspective. In: J. C. Lee and K. J. Kennedy, eds., Theorizing teaching and learning in Asia and Europe: A conversation between Chinese curriculum and European didactics. London and New York: Routledge, pp. 124-139.

Hopmann, S. (2015). 'Didaktik meets Curriculum' revisited: Historical encounters, systematic experience, empirical limits. Nordic Journal of Studies in Educational Policy, 1(1), pp. 14-21. https://doi.org/10.3402/nstep.v1.27007.

Jiang, Y. G. (2015). On quality science inquiry teaching. Teacher Education Research, 27(5), pp. 60-65 [In Chinese].

Kairov, I. (1953). Pedagogy (Translated by Y. Shen, Z. Nan, Z. H. Bei, B. H. Lu and C. P. Huang). Beijing: People's Education Press.

Lee, J. C. and Kennedy, K. J., eds. (2017). Theorizing teaching and learning in Asia and Europe: A conversation between Chinese curriculum and European didactics. London and New York: Routledge.

Liu, Z. X. (1990). Didactics of chemistry, 1st ed. Beijing: Higher Education Press. [In Chinese]. Liu, Z. X. (2018). Didactics of chemistry, 5th ed. Beijing: Higher Education Press. [In Chinese]. 
Pinar, W. (2011). From autobiography to allegory. In: What is curriculum theory?, 3rd ed. New York: Routledge, pp. 23-33.

Pinar, W. (2014). Curriculum studies in China: Reform, culture, history. In: W. Pinar, ed., Curriculum studies in China. New York: Palgrave Macmillan, pp. 223-246.

Strømnes, A. L., Rørvik, H. and Eilertsen, T. (1997). Didactical thinking and research in Norway during the four last decades. Scandinavian Journal of Educational Research, 41(3), pp. 237-258.

Wang, C. S. (1985). A seminar notes on didactics. Beijing: People's Education Press. [In Chinese].

Wang, C. S. (1988/2002). Theory of knowing in teaching-learning. Beijing: Beijing Normal University Press. [In Chinese].

Wang, Z-h. (2012). Process and pluralism: Chinese thought on the harmony of diversity. Frankfurt, Paris, Lancaster and New Brunswick: Ontos Verlag.

Wei, B. (2012). In pursuit of professionalism in the field of chemistry education in China: The story of Zhixin Liu. International Journal of Science Education, 34(13), pp. 1971-1989.

Westbury, I., Hopmann, S. and Riquarts, K. (2000). Teaching as a reflective practice: The German Didaktik tradition. Mahwah, NJ: Lawrence Erlbaum Associates.

$\mathrm{Xu}, \mathrm{J}$. C. (2019). The review of and reflection on the construction of didactics in China over the past 70 years. Education Sciences in China, 2(4), pp. 23-37 [In Chinese].

Zhang, H. (2017). Curriculum reform and research in China: A social-historical perspective. In: J. C. Lee and K. J. Kennedy, eds., Theorizing teaching and learning in Asia and Europe: A conversation between Chinese curriculum and European didactics. London and $\mathrm{New}$ York: Routledge. 